\title{
Prevalence and Risk Factors of Self-Reported Perfume Sensitivity in Saudi Arabia
}

\author{
Meshael Alrasheed*(D), Omar Albalawi (D), Mohammed Aljallal and Amani S. Alqahtani \\ Saudi Food and Drug Authority, Riyadh 13513, Saudi Arabia; ombalawi@sfda.gov.sa (O.A.); \\ majallal@sfda.gov.sa (M.A.); as.qahtani@sfda.gov.sa (A.S.A.) \\ * Correspondence: Mmrasheed@sfda.gov.sa; Tel.: +966-112-038-222 (ext. 3052)
}

check for updates

Citation: Alrasheed, M.; Albalawi, O.; Aljallal, M.; Alqahtani, A.S. Prevalence and Risk Factors of Self-Reported Perfume Sensitivity in Saudi Arabia. Healthcare 2021, 9, 1248 https://doi.org/10.3390/

healthcare 9101248

Academic Editor: Mustafa Z. Younis

Received: 22 June 2021

Accepted: 31 August 2021

Published: 22 September 2021

Publisher's Note: MDPI stays neutral with regard to jurisdictional claims in published maps and institutional affiliations.

Copyright: (c) 2021 by the authors. Licensee MDPI, Basel, Switzerland. This article is an open access article distributed under the terms and conditions of the Creative Commons Attribution (CC BY) license (https:// creativecommons.org/licenses/by/ $4.0 /)$.

\begin{abstract}
Perfumes are widely used products; however, several fragrance substances used in perfuming are well-established allergenic substances and have been attributed to various adverse health reactions. The nature and significance of perfume sensitivity reactions have not been thoroughly investigated. Therefore, this study aimed to identify the prevalence, nature, and associated risk factors of self-reported perfume sensitivity among the general population in Saudi Arabia. A nationally representative cross-sectional study was conducted among adults in Saudi Arabia in October 2020. Significant associated risk factors were explored using multivariate regression analyses. A total of 1078 participants completed the survey, with a mean age of 36.7 years (SD \pm 10.36$)$. Perfume sensitivity reactions were reported in $14.6 \%$ of participants. From among these participants, $17.8 \%$ reported moderate to severe reactions. Respiratory and skin symptoms were the most reported reactions, with total rates of $40.1 \%$ and $35.7 \%$, respectively. History of asthma $(\mathrm{OR}=3.2,95 \% \mathrm{CI}$ $1.88-4.37, p<0.001)$ and the use of counterfeit perfume products $(\mathrm{OR}=1.9,95 \% \mathrm{CI} 1.23-2.94, p<0.003)$ were significantly associated with a higher risk of perfume sensitivity. Our study revealed that a considerable number of the general population in Saudi Arabia has experienced adverse health reactions due to perfume products. The enormous volume of the perfume market thus necessitates further quantitative analysis studies to determine the presence of allergenic fragrance substances in perfumes.
\end{abstract}

Keywords: perfumes; fragrances; sensitivity; respiratory; dermatology; asthma

\section{Introduction}

Fragrance sensitivity is a health condition characterized by the experience of adverse health effects from exposure to a fragranced product [1]. Most commonly reported fragrance reactions include skin, respiratory, neurological, and nasal symptoms [2]. Perfumes have been reported as one of the fragranced products that contribute to fragrance sensitivity in several international studies [3,4]. A total rate of $32.2 \%$ of the public reported sensitivity to fragranced products, including perfumes, in a study that included four different countries [4]. In Saudi Arabia, 50.6\% of the participants of a study reported at least one adverse reaction from cosmetic products, including perfumes [5]. Fragrance substances added to cosmetic products and perfumes contributed to the majority of health adverse reactions caused by fragranced products [1,2].

Fragrance substances are natural or synthetic organic compounds with various attractive characteristics and effects. They are widely used in perfumes for their pleasant smell. A single perfume formula can contain several fragrance substances [2,6]. Many of the commonly used fragrances in perfuming are well-known contact allergens that have been attributed to different types of adverse reactions [2]. The EU Scientific Committee on Consumer Safety listed 54 fragrance substances and 28 natural extracts that have been identified as "established contact allergens in humans" [6]. Currently, there is no regulation in Saudi Arabia that requires the disclosure of perfume contents. 
The growth rate of the perfume market in Saudi Arabia sharply increased by $25.9 \%$ in 2014, with total sales of about 3.5 Billion Saudi Riyals [7]. Taking into account the huge market volume, studies targeting the safety of perfumes in the Saudi market are still lacking. In addition, the prevalence of hypersensitivity reactions caused by perfumes among the public in Saudi Arabia have not yet been investigated. Therefore, the main objectives of this study were to identify the prevalence, nature, and associated risk factors of perfume hypersensitivity reactions among the general population in Saudi Arabia.

\section{Materials and Methods}

\subsection{Study Design}

A cross-sectional study was conducted among adults aged 18 years or older in October 2020. Residents of the capital cities of the five main regions in Saudi Arabia-the Central, Northern, Southern, Eastern, and Western Region-were included. This study has been reviewed and approved by the Human Research Ethics Committee of the Saudi Food and Drug Authority (Approval number: 2020_007).

\subsection{Sample Size}

We used the proportional quota sampling technique to ensure that respondents were demographically representative of the general population. The sample population was divided according to region and gender distribution of the general population, based on the latest published census data (2017) [8]. The sample size was calculated at a confidence level of $95 \%$, and a $3 \%$ margin error; we estimated that a minimum sample size of 1068 participants would be sufficient. Moreover, we considered a 10\% response rate from the total recruited sample of 10,680 .

\subsection{Recruitment Method}

A list of participants generated from a governmental database (Saudi Food and Drug Authority) was chosen randomly based on region and gender, and the selected individuals were invited to participate in the study. Participants were invited using a text message (SMS) containing a short description of the study and the survey link. Each user had a unique device identifier linked to the research database; hence, the user could not submit information more than once. A consent letter in the first section of the survey was provided to all participants before their participation in the study survey. Data were obtained electronically, and no user could submit responses that were missing vital information. Phone interviews using CATI (computer assessed telephone interviewing) were conducted to follow up those who did not respond to the text message invitation.

\subsection{Research Tool}

We developed a survey comprised of four major parts. The first part aimed to assess the socio-demographic characteristics of the respondents, including age, gender, education level, monthly income, past medical history, previous dermatological disease, and the use of dermatological agents. The questions in the second part were about the participants' perfume-buying behaviors, and it included the following: perfume-buying sources, used perfume types and brands, and the tendency to check perfume authenticity before buying. Perfume types were classified into four groups: Parfum, 20-30\%, Eau de Toilette, 5-15\%, Eau de cologne, 2-4\%, and Perfume Oils [2].

In the third part, we assessed the history of perfume sensitivity by asking the participant if he/she had experienced any health problems when exposed to perfume products. If the answer was "Yes", they were asked detailed questions about the type of reactions, duration, recurrence, need for medical care, and symptoms resolution. The fourth part included questions about the perceived causes of sensitivity and the reporting behaviors of those who developed sensitivity reactions caused by perfumes. 


\subsection{Outcome Measures}

The primary outcome measures for the study were the prevalence and the associated risk factors of self-reported perfume sensitivity among adults in Saudi Arabia. Perfume sensitivity was identified by the report of any of the following symptoms: skin symptoms (redness, itching, blistering, discoloration), respiratory symptoms (difficulty in breathing, shortness of breath, cough), nasal symptoms (nasal congestion, sneezing, runny nose), or neurological (headache, dizziness, migraine, loss of coordination) $[4,9]$.

Mild reactions were identified by the report of any of the listed symptoms without the need for medical care, whereas moderate/severe reactions were identified by the report of one or more of the skin or respiratory tract reactions, the need for medical care, and the duration of the reported symptom. Assessed associated sensitivity risk factors included participants' demographics, past medical and dermatological histories, medication use, and used perfume types and brands. Secondary outcomes included perfume-buying behaviors, the perceived causes of sensitivity, and reporting behaviors among study participants.

\subsection{Statistical Analyses}

A descriptive analysis summarized by mean and standard deviation for continuous variables and percentages for categorical variables was conducted for all study variables. A binomial logistic regression analysis was used to identify perfume sensitivity risk factors, including demographics, past medical history, previous dermatological diseases, and the use of dermatological agents. Regression coefficients, odds ratios (ORs), 95\% confidence intervals (CIs), and $p$ values to quantify the associations between variables and study outcomes were reported. The statistical significance level was set at $p<0.05$ (two-sided). All analyses were performed using R software (version 4.0.3).

\section{Results}

\subsection{Social-Demographic Characteristics and Perfume Sensitivity Prevalence}

A total of 1078 participants (mean age 36.7 years $(S D \pm 10.36)$ ) completed the survey, with a response rate of $10 \%$. From among the participants, $157(14.4 \%)$ self-reported the experience of at least one perfume hypersensitivity reaction. More details of the participants characteristics are presented in Table 1.

Table 1. Socio-demographic characteristics among study participants $(n=1078)$.

\begin{tabular}{cccc}
\hline & Total Sample (\%) & \multicolumn{2}{c}{ Self-Reported Perfume Sensitivity } \\
\hline Overall & $1078(100)$ & $157(14.6)$ & No \\
\hline Age & & & $921(84.4)$ \\
\hline $18-30$ & $331(30.7)$ & $36(22.9)$ & $295(32)$ \\
\hline $31-45$ & $548(50.8)$ & $93(59.2)$ & $455(49.4)$ \\
\hline$\geq 46$ & $199(18.5)$ & $28(17.9)$ & $181(18.6)$ \\
\hline Gender & & & \\
\hline Male & $644(59.7)$ & $110(70.1)$ & $334(58)$ \\
\hline Female & $434(40.3)$ & $47(29.9)$ & \\
\hline Nationality & & $147(93.6)$ & $659(93.3)$ \\
\hline Saudi & $1006(93.3)$ & $10(6.4)$ & \\
\hline Not Saudi & $72(6.7)$ & & \\
\hline Marital status & & $50(31.8)$ & $32(3.5)$ \\
\hline Single & $340(31.5)$ & $98(62.4)$ &
\end{tabular}


Table 1. Cont.

\begin{tabular}{|c|c|c|c|}
\hline & \multirow[t]{2}{*}{ Total Sample (\%) } & \multicolumn{2}{|c|}{ Self-Reported Perfume Sensitivity } \\
\hline & & Yes & No \\
\hline \multicolumn{4}{|l|}{ Education } \\
\hline High school or less & $251(23.3)$ & $29(18.4)$ & $128(13.9)$ \\
\hline Bachelor/Diploma & $624(57.9)$ & $102(65.3)$ & $640(69.5)$ \\
\hline Master/PhD & $203(18.8)$ & $26(16.3)$ & $153(16.6)$ \\
\hline \multicolumn{4}{|l|}{ Region } \\
\hline Central & $292(27)$ & $58(36.9)$ & $234(25.4)$ \\
\hline West & $335(31)$ & $45(28.7)$ & $290(31.5)$ \\
\hline Eastern Region & $177(16.1)$ & $22(14)$ & $150(16.3)$ \\
\hline South & $139(12.9)$ & $13(8.3)$ & $126(13.7)$ \\
\hline North & $140(13)$ & $19(12.1)$ & $121(13.1)$ \\
\hline \multicolumn{4}{|l|}{ Monthly income } \\
\hline Less than $5000 \mathrm{SR}$ & $153(14.2)$ & $27(17.2)$ & $126(13.7)$ \\
\hline $5000-10,000$ SR & $227(21.1)$ & $28(17.8)$ & $199(21.6)$ \\
\hline $10,000-15,000 \mathrm{SR}$ & $200(18.6)$ & $40(25.5)$ & $160(17.4)$ \\
\hline 15,000 SR or more & $197(18.3)$ & $31(19.7)$ & $166(18)$ \\
\hline I prefer not to say & $301(28)$ & 31 (19.7) & $270(29.3)$ \\
\hline \multicolumn{4}{|c|}{ Previous dermatological diagnosis } \\
\hline No & $875(81.2)$ & $108(68.8)$ & $767(83.3)$ \\
\hline Yes & $203(18.8)$ & $49(31.2)$ & $154(16.7)$ \\
\hline \multicolumn{4}{|c|}{ Reported dermatological diseases * } \\
\hline Eczema & $82(7.6)$ & $17(10.8)$ & $65(7.1)$ \\
\hline Vitiligo & $9(0.83)$ & $2(1.3)$ & $7(0.8)$ \\
\hline Psoriasis & $26(2.4)$ & $4(2.5)$ & $22(2.4)$ \\
\hline Allergies & $91(8.3)$ & $28(17.8)$ & $62(6.7)$ \\
\hline Acne & $41(3.8)$ & $7(4.5)$ & $13(1.4)$ \\
\hline \multicolumn{4}{|c|}{ Regular use of dermatological agents } \\
\hline No & $1014(94.1)$ & $142(90.4)$ & $872(94.7)$ \\
\hline Yes & $64(5.9)$ & $15(9.6)$ & $49(5.3)$ \\
\hline \multicolumn{4}{|c|}{ Previous medical diagnosis } \\
\hline No & $624(77.5)$ & $110(70.1)$ & $725(78.7)$ \\
\hline Yes & $243(22.5)$ & $47(29.9)$ & $196(21.3)$ \\
\hline \multicolumn{4}{|c|}{ Reported medical conditions $\S$} \\
\hline Diabetes Mellitus & $88(8.2)$ & $8(5.1)$ & $80(8.7)$ \\
\hline Hypertension & $81(7.5)$ & $14(8.9)$ & $67(7.3)$ \\
\hline Asthma & $86(8)$ & $28(17.8)$ & $62(6.7)$ \\
\hline Heart disease & $29(0.07)$ & $8(5.1)$ & $21(2.3)$ \\
\hline Autoimmune & $18(0.2)$ & $5(3.2)$ & $13(1.4)$ \\
\hline
\end{tabular}

* Among those who reported previous dermatological diagnosis. ${ }^{\S}$ Among those who reported medical conditions.

\subsection{Characteristics of Self-Reported Perfume Sensitivity Reactions}

Among all participants with perfume sensitivity, respiratory symptoms and skin symptoms were the most reported reactions, with total rates of $40.1 \%$ and $35.7 \%$, respectively. About $29 \%$ of participants reported nasal symptoms, whereas headache was the least reported symptom, with a rate of $10.4 \%$. The most reported perfume type that caused sensitivity was Parfum (47.8\%), and most of the reported products were unknown/counterfeit products $(43.3 \%)$. Around $22 \%$ of participants with perfume sensitivity reported that their 
symptoms lasted more than a day, and $20 \%$ of them reported the need for medical care during their experience.

Mild reactions were reported in $82.2 \%$ of the participants, whereas moderate/severe reactions were found in $17.8 \%$ of the participants. Parfum and unknown/counterfeit products were the most reported type and brand of moderate/severe reactions, with percentages of $53.6 \%$ and $46.4 \%$, respectively. Most participants $(93 \%)$ reported a total resolution of the symptoms after stopping the perfume. Sensitivity recurrence was reported in $66.2 \%$ of participants, with $15.9 \%$ reporting the same experience with different perfume types and brands (Table 2).

Table 2. Self-reported perfume sensitivity among study participants $(n=157)$.

\begin{tabular}{|c|c|c|}
\hline & & Participants, $n(\%)$ \\
\hline \multicolumn{3}{|l|}{ Reported perfume type } \\
\hline & Parfum $20-30 \%$ & $75(47.8)$ \\
\hline & Perfume oils & $35(22.2)$ \\
\hline & Eau de Toilette 5-15\% & $29(18.5)$ \\
\hline & Eau de cologne $2-4 \%$ & $18(11.5)$ \\
\hline \multicolumn{3}{|l|}{ Reported perfume brand } \\
\hline & Unknown/counterfeit-origin products & $68(43.3)$ \\
\hline & Imported brands & $37(23.6)$ \\
\hline & Domestic brands & $49(31.2)$ \\
\hline \multicolumn{3}{|l|}{ Reported reactions } \\
\hline & Respiratory symptoms & $63(40.1)$ \\
\hline & Skin symptoms & $56(35.7)$ \\
\hline & Nasal symptoms & $45(28.7)$ \\
\hline & Neurological symptoms & $17(10.4)$ \\
\hline & Others & $9(5.7)$ \\
\hline \multicolumn{3}{|l|}{ Reported sensitivity duration } \\
\hline & Less than an hour & $53(33.8)$ \\
\hline & An hour to $24 \mathrm{~h}$ & $69(44)$ \\
\hline & A day or more & $35(22.2)$ \\
\hline \multicolumn{3}{|l|}{ The need for medical care } \\
\hline & Yes & $31(19.7)$ \\
\hline & No & $126(80.3)$ \\
\hline \multicolumn{3}{|l|}{ Sensitivity severity } \\
\hline & Mild & $129(82.2)$ \\
\hline & Moderate/severe & $28(17.8)$ \\
\hline \multicolumn{3}{|l|}{ Sensitivity resolution } \\
\hline & Yes & $146(93)$ \\
\hline & No & $11(7)$ \\
\hline \multicolumn{3}{|l|}{ Sensitivity recurrence } \\
\hline & One time only & $53(33.8)$ \\
\hline & More than once with the same product & $49(31.2)$ \\
\hline & $\begin{array}{l}\text { More than once with different products from } \\
\text { the same perfume type }\end{array}$ & $30(19.1)$ \\
\hline & $\begin{array}{l}\text { More than once with different products from } \\
\text { different perfume types }\end{array}$ & $25(15.9)$ \\
\hline
\end{tabular}




\subsection{Perfume-Buying Behavior}

Shopping malls and online shopping were the most reported sources of perfume buying among all study participants, with percentages of $76.7 \%$ and $53.4 \%$, respectively (Figure 1). The most used perfume types were Parfum $66.4 \%$, followed by Perfume oils $45.3 \%$, Eau de Toilette $43.4 \%$, and Eau de cologne $22.6 \%$. Imported and domestic brand products were highly used among study participants, whereas the use of unknown/counterfeit products was reported in $15 \%$ of participants. About $45 \%$ of participants reported that they do not always verify perfume authenticity before buying. Full details are reported in Table 3.

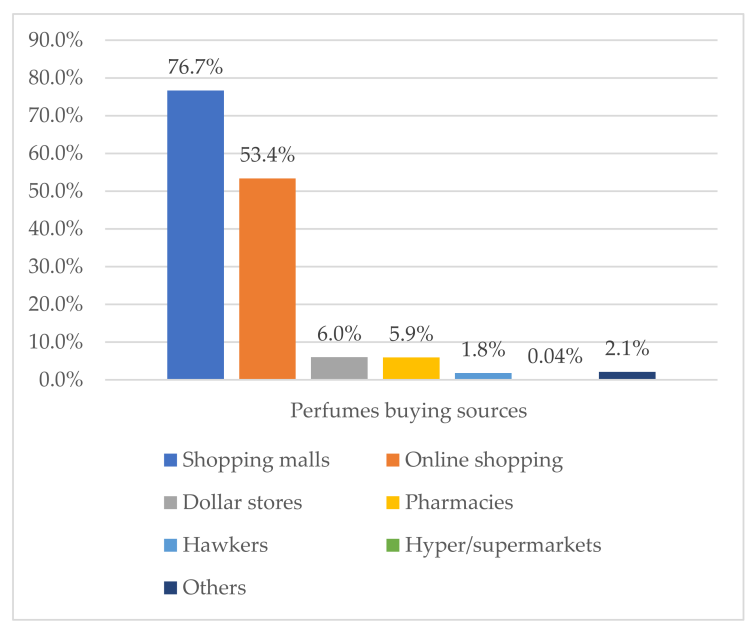

Figure 1. Perfume-buying sources among study participants $(n=1078)$.

Table 3. Perfume-buying behaviors among study participants $(n=1078)$.

\begin{tabular}{|c|c|c|}
\hline & & Participants, $n(\%)$ \\
\hline \multicolumn{3}{|l|}{ Used perfume types } \\
\hline & Parfum $20-30 \%$ & $716(66.4)$ \\
\hline & Eau de Toilette $5-15 \%$ & $468(43.4)$ \\
\hline & Eau de cologne $2-4 \%$ & $244(22.6)$ \\
\hline & Perfume oils & $488(45.3)$ \\
\hline \multicolumn{3}{|l|}{ Used perfume brands } \\
\hline & Imported brands & $837(77.4)$ \\
\hline & Domestic brands & $738(68.2)$ \\
\hline & Unknown/counterfeit origins products & $164(15)$ \\
\hline \multicolumn{3}{|c|}{$\begin{array}{l}\text { Verifying perfume authenticity } \\
\text { before buying }\end{array}$} \\
\hline & Always & $480(44.5)$ \\
\hline & Sometimes & $288(27.8)$ \\
\hline & Never & $310(28.8)$ \\
\hline \multicolumn{3}{|l|}{$\begin{array}{l}\text { Why? (If the answer is } \\
\text { "sometimes" or "never" }\end{array}$} \\
\hline & I only buy from branded shops & $313(52.3)$ \\
\hline & I do not care about this information & $89(14.9)$ \\
\hline & $\begin{array}{l}\text { I do not know where I can find this } \\
\text { information }\end{array}$ & $191(31.9)$ \\
\hline & $\begin{array}{l}\text { I do not mind buying unknown/counterfeit } \\
\text { perfumes }\end{array}$ & $48(8)$ \\
\hline & Others & $11(1.8)$ \\
\hline
\end{tabular}




\subsection{Perfume Sensitivity—Associated Risk Factors}

Multivariate logistic regression was used to identify the associated risk factors of perfume sensitivity. The model assessed the association of the demographic characteristics and past medical history with the risk of perfume sensitivity. It showed that a history of asthma diagnosis (OR $=3.2,95 \% \mathrm{CI} 1.88-4.37, p<0.001)$ and the use of unknown/counterfeit perfume products $(\mathrm{OR}=1.9,95 \% \mathrm{CI} 1.23-2.94, p<0.003)$ were significantly associated with a higher risk of self-reported perfume sensitivity (Table 4).

Table 4. Multivariate regression analysis of perfume sensitivity risk factors.

\begin{tabular}{cccc}
\hline & OR & $\mathbf{9 5 \%}$ CI & $p$ Value \\
\hline Gender & 1.8 & $0.87-3.79$ & 0.115 \\
\hline History of dermatological disease & 1.37 & $0.72-2.45$ & 0.304 \\
\hline Regular use of dermatological drugs & 1.16 & $0.54-2.38$ & 0.685 \\
\hline History of skin allergy & 0.88 & $0.94-2.81$ & 0.091 \\
\hline History of asthma & 3.2 & $1.88-4.37$ & $<0.001$ \\
\hline The use of domestic perfume products & 0.9 & $0.59-1.37$ & 0.626 \\
\hline The use of unknown/counterfeit products & 1.9 & $1.23-2.94$ & 0.003 \\
\hline
\end{tabular}

\subsection{Perfume Sensitivity Perceptions and Reporting Behaviors}

About $55 \%$ of those who self-reported perfume sensitivity attributed their experience to the presence of allergens in the perfume, whereas $24.8 \%$ thought that it was because they were allergic to perfumes (Figure 2). Only 1.3\% reported their reactions to the responsible authorities. The main reason for the non-reporting was their lack of knowledge of the responsible authority. Other reasons are represented in Table 5.

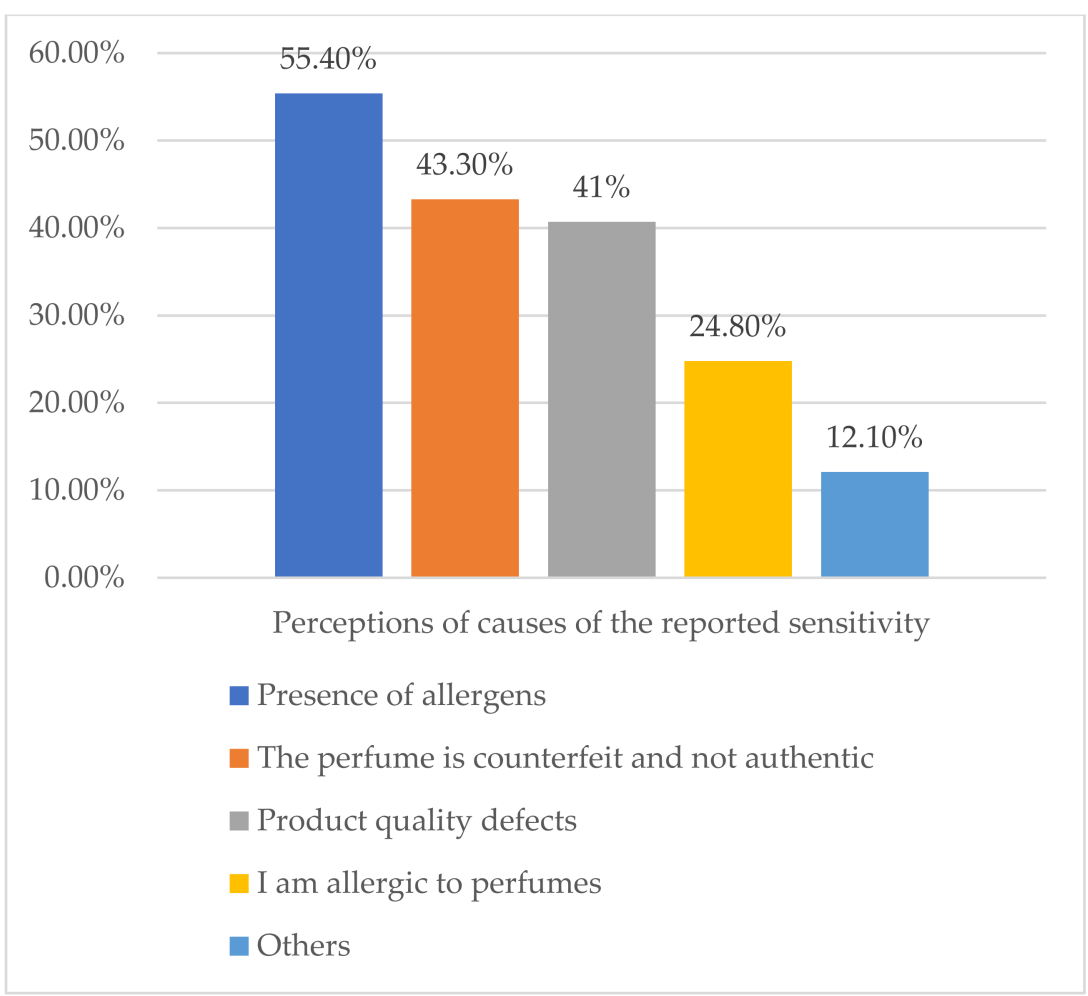

Figure 2. Perceptions of causes of the reported sensitivity $(n=157)$. 
Table 5. Perfume allergy perceptions and reporting behavior among participants $(n=157)$.

\begin{tabular}{cc}
\hline & Participants, $\boldsymbol{n} \mathbf{( \% )}$ \\
\hline Perception of causes of the reported sensitivity & \\
\hline Presence of allergens & $87(55.4)$ \\
\hline Product quality defects & $64(40.7)$ \\
\hline The perfume is counterfeit and not authentic & $68(43.3)$ \\
\hline I am allergic to perfumes & $39(24.8)$ \\
\hline Others & $19(12.1)$ \\
\hline Allergy incident reporting & $1(0.6)$ \\
\hline Yes, to Ministry of Commerce & $1(0.6)$ \\
\hline No Nousons for not reporting the incident * Food and Drug Authority & $155(98.8)$ \\
\hline I do not know the responsible authority & $99(63.9)$ \\
\hline I do not know how to contact the responsible authority & $70(45.2)$ \\
\hline I do not care to report & $25(16.1)$ \\
\hline O Others & $24(15.5)$ \\
\hline
\end{tabular}

\section{Discussion}

The results of this study indicate that $14.7 \%$ of the population in Saudi Arabia have experienced at least one of the perfume reactions. Our study investigated further and showed that previous history of asthma and the use of unknown/counterfeit products were significantly associated with the higher risk of perfume sensitivity among participants. Studies targeting the safety of perfume products exclusively are rare, and this study, to our knowledge, is the first epidemiological study that has targeted perfume products in the area.

A study conducted recently among 425 adults in the Eastern Province of Saudi Arabia reported that $50.6 \%$ of the participants had an adverse reaction from a fragranced product, including perfumes [5]. Internationally, a study conducted across four countries, including the United States, the United Kingdom, Australia, and Sweden showed that $32.2 \%$ of the participants reported sensitivity from fragranced products, including perfumes [4]. Furthermore, $34.7 \%$ of the population in the United States reported the experience of different health problems upon exposure to fragranced products [3]. In all these studies, perfumes were reported as one of the fragranced products that contributed to the reported health reactions [3-5]. The lower rate in our study can be justified by the fact that we targeted perfume products exclusively, while other studies included all types of fragranced products during their assessment.

Respiratory and skin symptoms were the most reported reactions among the participants in our study, with total rates of $40.1 \%$ and $35.7 \%$, respectively. These results were consistent with the results of the international study, where they found respiratory and skin symptoms to be the most reported symptoms [3,4]. Reported skin symptoms in our study cannot be classified as allergic contact dermatitis without performing patch testing. However, positive patch test reactions to perfumes have been investigated previously $[10,11]$. A study conducted among female nurses showed that fifteen had a positive patch test reaction to a perfume mix of eight different perfume ingredients, and twelve of the fifteen reported previous perfume sensitivity [12]. Moreover, perfumes were the most frequent source of allergic contact dermatitis caused by fragranced products in a case-control study of eczema patients [13]. 
The significant associated risk factors identified in our study include a previous history of asthma and the use of unknown/counterfeit products. The association between asthma diagnosis and perfume sensitivity was previously identified $[3,14]$. A study that included 1137 asthmatics found that $64.3 \%$ of them reported one or more types of adverse health effects resulting from fragranced products [14]. In addition, the prevalence of fragrance sensitivity was higher among asthmatics than the general population in the United States. The association between the use of unknown/counterfeit perfume products and the risk of perfume sensitivity was not investigated before. Interestingly, our results showed that about $19 \%$ of those who reported perfume sensitivity in our study needed medical care for their reaction, which amplify the clinical irrelevance of the majority of the reported reactions. However, taking into consideration the nature of our study (self-reporting), the accuracy and the clinical significance of the reported reactions cannot be confirmed.

\subsection{Strengths and Limitations}

This is the first study in Saudi Arabia that assessed the adverse health reactions associated with exposure to perfumes. The participants in this study were recruited randomly from a governmental database and divided according to region and gender. The weighted distributions of respondents by age, gender, and region were consistent with 2018 estimates from the Saudi Arabian General Authority for Statistics of the five main regions in Saudi Arabia (Central region, Western, Eastern, Southern, and Northern regions) [8]. Despite the significant results, our study has some limitations. This was a cross-sectional study that was based on self-reported data from participants, risk of reporting bias exist. Due to the low response rate, two data collection methods were used (web-based survey and phone interviews); however, no significant difference was found between the results of these two methods. Lastly, we did not assess the history of previous food or drug allergies among participants.

\subsection{Future Directions}

The highly predicted expansion of the perfume market highlights the need for further research in order to assess the safety of the available perfume products in the market. Quantitative studies are recommended to determine the composition and the presence of allergenic fragranced substances in the available perfume products. Lastly, an assessment of the societal effects of the experience of perfume sensitivity can be considered in future studies to understand the social extent of the problem [15].

\section{Conclusions}

Our study reveals that a considerable number of the general population in Saudi Arabia reports having experienced adverse health reactions from perfume products. The results of our study offer an insight into the safety of current perfume products available in the Saudi market. Future quantitative studies that determine the composition and the presence of fragranced allergens in the available perfume products are highly needed.

Author Contributions: M.A. (Meshael Alrasheed): conceptualization, methodology, analysis, writingoriginal draft, visualization; O.A.: investigation, data curation, writing-review and editing; M.A. (Mohammed Aljallal): conceptualization, methodology, writing-review and editing; A.S.A.: conceptualization, methodology, supervision, writing-review and editing. All authors have read and agreed to the published version of the manuscript.

Funding: This research received no external funding.

Institutional Review Board Statement: The study was conducted according to the guidelines of the Declaration of Helsinki, and approved by the Institutional Review Board of the Saudi Food \& Drug Authority (2020_007).

Informed Consent Statement: Informed consent was obtained from all subjects involved in the study.

Data Availability Statement: Not applicable. 
Conflicts of Interest: The authors declare no conflict of interest.

Disclaimer: Conclusions reached in this article are based on the personal scientific interpretations of the authors and do not necessarily represent the opinion of the Saudi Food and Drug Authority (SFDA).

\section{References}

1. Uter, W. Contact allergy to fragrances: Current clinical and regulatory trends. Allergol. Sel. 2017, 1, 190-199. Available online: https: / / www.dustri.com/article_response_page.html?artId=16041\&doi=10.5414/ALX01604E\&L=0 (accessed on 31 July 2021). [CrossRef] [PubMed]

2. Kumar, M.; Devi, A.; Sharma, M.; Kaur, P.; Mandal, U.K. Review on perfume and present status of its associated allergens J. Cosmet. Dermatol. 2021, 20, 391-399. [CrossRef] [PubMed]

3. Caress, S.M.; Steinemann, A.C. Prevalence of fragrance sensitivity in the American population. J. Environ. Health 2009, 71, 46-50. [PubMed]

4. Steinemann, A. International prevalence of fragrance sensitivity. Air Qual. Atmos. Health 2019, 12, 891-897. [CrossRef]

5. Lucca, J.M.; Joseph, R.; Al Kubaish, Z.H.; Al-Maskeen, S.M.; Alokaili, Z.A. An observational study on adverse reactions of cosmetics: The need of practice the Cosmetovigilance system. Saudi Pharm. J. 2020, 28, 746-753. Available online: https: / /linkinghub.elsevier.com/retrieve/pii/S1319016420301031 (accessed on 2 August 2021). [CrossRef] [PubMed]

6. Dornic, N.; Ficheux, A.S.; Roudot, A.C. Qualitative and quantitative composition of essential oils: A literature-based database on contact allergens used for safety assessment. Regul. Toxicol. Pharmacol. 2016, 80, 226-232. Available online: https://linkinghub. elsevier.com/retrieve/pii/S027323001630174X (accessed on 2 August 2021). [CrossRef] [PubMed]

7. Fragrances in Saudi Arabia Euromonitor. 2016. Available online: https://www.euromonitor.com/fragrances-in-saudi-arabia/ report (accessed on 6 August 2021).

8. General Authority for Statistics. Population in Saudi Arabia by Age, Nationality (Saudi/Non-Saudi) and Gender. 2018. Available online: https: / / www.stats.gov.sa/en (accessed on 2 October 2020).

9. Uter, W.; Johansen, J.D.; Börje, A.; Karlberg, A.T.; Lidén, C.; Rastogi, S.; Roberts, D.; White, I.R. Categorization of fragrance contact allergen for prioritization of preventive measures: Clinical and experimental data and consideration of structure-activity relationships. Contact Dermat. 2013, 69, 196-230. [CrossRef] [PubMed]

10. Frosch, P.J.; Pilz, B.; Andersen, K.E.; Burrows, D.; Camarasa, J.G.; Dooms-Goossens, A.; Ducombs, G.; Fuchs, T.; Hannusksela, M.; Lachapelle, J.M.; et al. Patch testing with fragrances: Results of a multicenter study of the European Environmental and Contact Dermatitis Research Group with 48 frequently used constituents of perfumes. Contact Dermat. 1995, 33, 333-342. [CrossRef] [PubMed]

11. Soo Lim, D.; Min Choi, S.; Kim, K.B.; Yoon, K.; Kacew, S.; Sik Kim, H.; Lee, B.M. Determination of fragrance allergens and their dermal sensitization quantitative risk assessment (QRA) in 107 spray perfumes. J. Toxicol. Environ. Health Part A 2018, 81, 1173-1185. [CrossRef] [PubMed]

12. Guin, J.D.; Berry, V.K. Perfume sensitivity in adult females. A study of contact sensitivity to a perfume mix in two groups of student nurses. J. Am. Acad. Dermatol. 1980, 3, 299-302. [CrossRef]

13. Johansen, J.D. Fragrance Contact Allergy: A Clinical Review. Am. J. Clin. Dermatol. 2003, 4, 789-798. [CrossRef] [PubMed]

14. Steinemann, A. Fragranced consumer products: Effects on asthmatics. Air Qual. Atmos. Health 2018, 11, 3-9. [CrossRef] [PubMed]

15. Steinemann, A. Health and societal effects from exposure to fragranced consumer products. Prev. Med. Rep. 2017, 5, 45-47. [CrossRef] [PubMed] 